\title{
A pilot study to evaluate the effect of Taeumjowi- tang on obesity in Korean adults: study protocol for a randomised, double-blind, placebo- controlled, multicentre trial
}

\author{
Sunju Park ${ }^{1,2}$, Jeong-Su Park ${ }^{1,2}$, ChunHoo Cheon ${ }^{1,2}$, Yong Joon Yang ${ }^{2}$, Changsuk An², Bo-Hyoung Jang ${ }^{2}$, \\ Yun-Kyung Song ${ }^{3}$, Hoyeon Go ${ }^{4}$, Ju Ah Lee ${ }^{5}$, Yongcheol Shin ${ }^{2}$ and Seong-Gyu Ko $0^{1,2^{*}}$
}

\begin{abstract}
Background: Obesity, which is described as excessive or abnormal body fat, increases the risk of diet-related diseases. In Korea and around the world, the prevalence of obesity has grown annually from 1998 to 2008. This growth has continued despite various therapeutic efforts. The discovery of new and alternative treatments for obesity should be considered an important priority. Taeumjowi-tang (TJ001), a traditional Korean medicinal extract consisting of eight herbs, is a widely used herbal remedy for obesity in Korea. However, the efficacy and safety of TJ001 have not been fully investigated in a clinical trial. The purpose of this pilot study is to estimate obesityrelated parameters and to assess the efficacy and safety of TJ001.

Methods: Our study is a randomised, double-blind, placebo-controlled, multicentre clinical trial of Taeumjowi-tang (TJ001). For this study, we will recruit obese Korean patients of both sexes, ages 18 to 65 years, from four university hospitals. A total of 104 subjects will be recruited. The participants will receive either $7 \mathrm{~g}$ of TJ001 or a placebo three times daily for 12 weeks. The primary end point will be the rate of subjects who lose at least $5 \%$ of their baseline body weight. The secondary end points will be changes in body weight, body mass index, waist circumference, hip circumference, waist/hip circumference ratio, lipid profiles, body fat composition, blood pressure, fasting glucose concentration, Creactive protein and questionnaires related to the quality of life. The outcomes will be measured every 4 weeks. The study period will be 12 weeks and will include a total of five visits with each subject (at screening and at 0, 4, 8 and 12 weeks).
\end{abstract}

Conclusions: The results of our study will inform various estimates of TJ001 and will serve as the basis for a largerscale trial. This study will assess the efficacy and safety of TJ001 as an alternative herbal remedy for obesity.

Trial registration: Current Controlled Trials ISRCTN87153759

Keywords: Taeumjowi-tang, obesity, efficacy, safety, randomised controlled trial

\section{Background}

The World Health Organisation (WHO) defines "obesity" as abnormal or excessive fat accumulation that may impair health [1]. Treatment of obesity is important because this chronic, noncommunicable disease causes not only a range of health problems, such as

\footnotetext{
* Correspondence: epiko@khu.ac.kr

${ }^{1}$ Center for Clinical Research and Genomics, College of Oriental Medicine and Institute of Oriental Medicine, Kyung Hee University, 1 Hoegi-dong, Seoul 130-701, Republic of Korea

Full list of author information is available at the end of the article
}

cardiovascular disease, various metabolic syndromes and certain cancers [1-3], but also social problems. In addition to the global incidence of obesity, obesity has become one of the most life-threatening problems in Korea. The Korea National Health and Nutrition Examination Survey showed that the overall prevalence of Korean adult obesity in 2008 was $30.7 \%$, compared with $21.8 \%$ in 1998 [4]. The survey defined adults as individuals who are at least 20 years old, and obesity was defined as a body mass index (BMI) $25 \mathrm{~kg} / \mathrm{m}^{2}$ according to the definition of the International Association for the

\section{C) Biomed Central}


study of Obesity in the Western Pacific Region of the WHO $[1,5]$.

Several nonpharmacological attempts to curb the increase in obesity, including dietary or exercise management, have been largely unsuccessful. These failures have encouraged specialists to develop treatments using pharmacotherapy [2]. Despite these therapeutic attempts, an efficacy and safety limit for conventional weight reduction therapies is apparent [6]. The demand for safe and effective anti-obesity agents is increasing, and herbal combinations are meeting those needs [7]. The relative importance and potential benefits of herbal preparations has extended their role as possible alternative methods for obesity therapies.

Taeumjowi-tang (TJ001; HANPOONG Pharm \& Foods Co Ltd, Jeonju-si, South Korea) is a traditional Korean medicine preparation that originated from I Je-ma's Sasang constitutional medicine theory [8]. This theory is representative of the individualised medical approach, which is widely used to diagnose and treat disease in Korea. The Sasang typology explains specific disease susceptibility and drug response differences through distinctive pathology types. Taeumjowi-tang (TJ001) is a decoction consisting of eight herbal ingredients and is usually prescribed for TaeEum persons (Greater Yin person, or Tae-Eum-In) to regulate stomach-related symptoms such as jaundice, anhidrosis, stuffiness and the sensation of fullness [8-10]. Owing to the unique pathology of Tae-Eum, these individuals gain weight more easily than the other three constitutional types (Tae-Yang, So-Eum and So-Yang). The Sasang typological formulary for Tae-Eum persons contains many therapies related to obesity. Among the various preparations, TJ001 has become the treatment regimen for obesity most widely used by Korean medical professionals [11-15], and its use has been expanded to all types of obesity. Preclinical results have supported the antiobesity and hypolipidaemic effects of TJ001 [16-19]; however, the results of clinical studies have been insufficient $[20,21]$. Although many large, placebo-controlled trials of herbal combinations and dietary supplements showing antiobesity effects have been reported [22-27], large-scale trials of Taeumjowi-tang have not yet been conducted.

This study will be the first reported randomised, doubleblind, placebo-controlled clinical trial of Taeumjowi-tang (TJ001) in obese adults in Korea. The main purpose of this study is to assess the efficacy and safety of medicinal herbal extract of Taeumjowi-tang through a 12-week randomised controlled trial (RCT) that produces obesityrelated estimates.

\section{Methods}

\section{Objectives and hypothesis} Objectives

The main objectives of this trial are to (1) evaluate the efficacy and safety of TJ001 in obese Korean adults, (2) explore estimates of obesity-related variables, including the amount of weight reduction, (3) discover the precise target population, (4) establish an appropriate primary end point and (5) estimate the proper treatment period. Hypothesis

We hypothesise that the TJ001 responder rates with a $5 \%$ or greater weight reduction will be higher than those in the placebo group. We also expect that use of TJ001 will be relatively safe.

\section{Study design and period}

This study is a 12-week randomised, double-blind, placebo-controlled, multicentre trial at four tertiary university hospitals. Figure 1 shows the schematic flow of the study.

\section{Study groups}

The study will include the following two arms: the TJ001 group (treatment arm) and the placebo group (control arm).

\section{Population}

The subjects will be obese Koreans of both sexes and ages 18 to 65 years.

\section{Eligibility criteria}

\section{Inclusion and exclusion criteria}

The inclusion and exclusion criteria are shown in Table 1.

\section{Subject withdrawal criteria}

The subjects who meet the criteria listed in Table 2 will be discontinued from treatment. The participants who will be withdrawn after randomisation will be followed for outcomes.

\section{Interventions}

Participating subjects assigned to either the treatment group or the placebo group will be instructed to take $7 \mathrm{~g}$ of TJ001 or placebo three times daily (a total of $21 \mathrm{~g}$ ) for 12 weeks (84 days). TJ001 (Taeumjowi-tang granule extract, HANPOONG Pharm \& Foods Co Ltd) is a compound of the powdered extract of several medicinal herbs, and the placebo will be similar to TJ001 in form, colour and odour. The components of TJ001 and the placebo are listed in Table 3.

\section{Lifestyle management}

Dietary intake and the type and intensity of exercise will be recorded by the research coordinator at every visit but will not be managed strictly.

\section{Dietary instructions}

For dietary counselling, the subjects will be counselled to consume 20 to $25 \mathrm{kcal} / \mathrm{kg}$. In other words, the participants will be asked to keep their dietary intake approximately at 1,500 kcal/day for men and 1,200 kcal/day for 


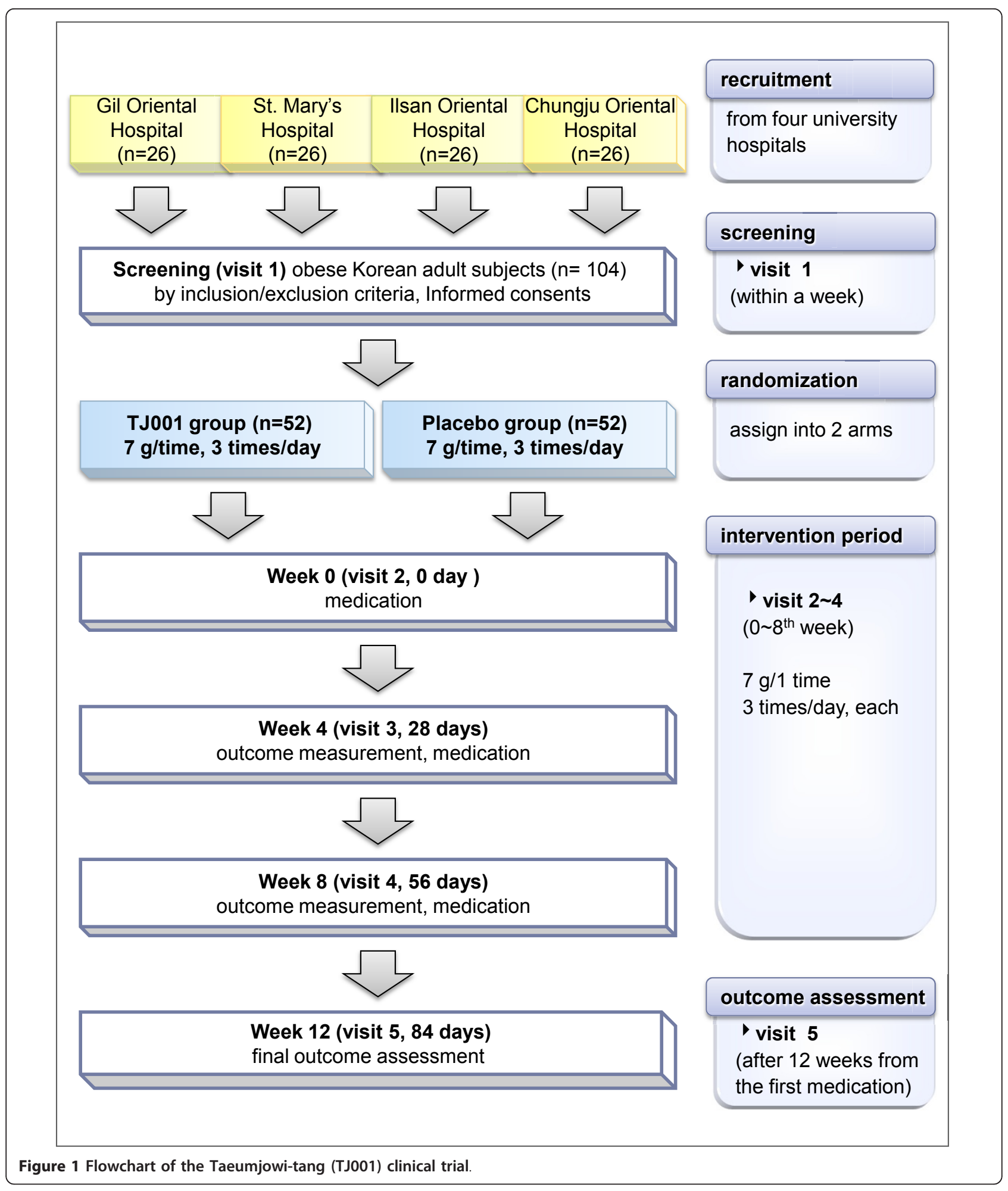

women. A dietary intake diary will be distributed to the subjects, and they will use a diary to calculate the number of calories consumed.
Exercise

As the trial will be conducted without lifestyle management, the participants will be allowed to maintain their 


\section{Table 1 Inclusion and exclusion criteria ${ }^{a}$}

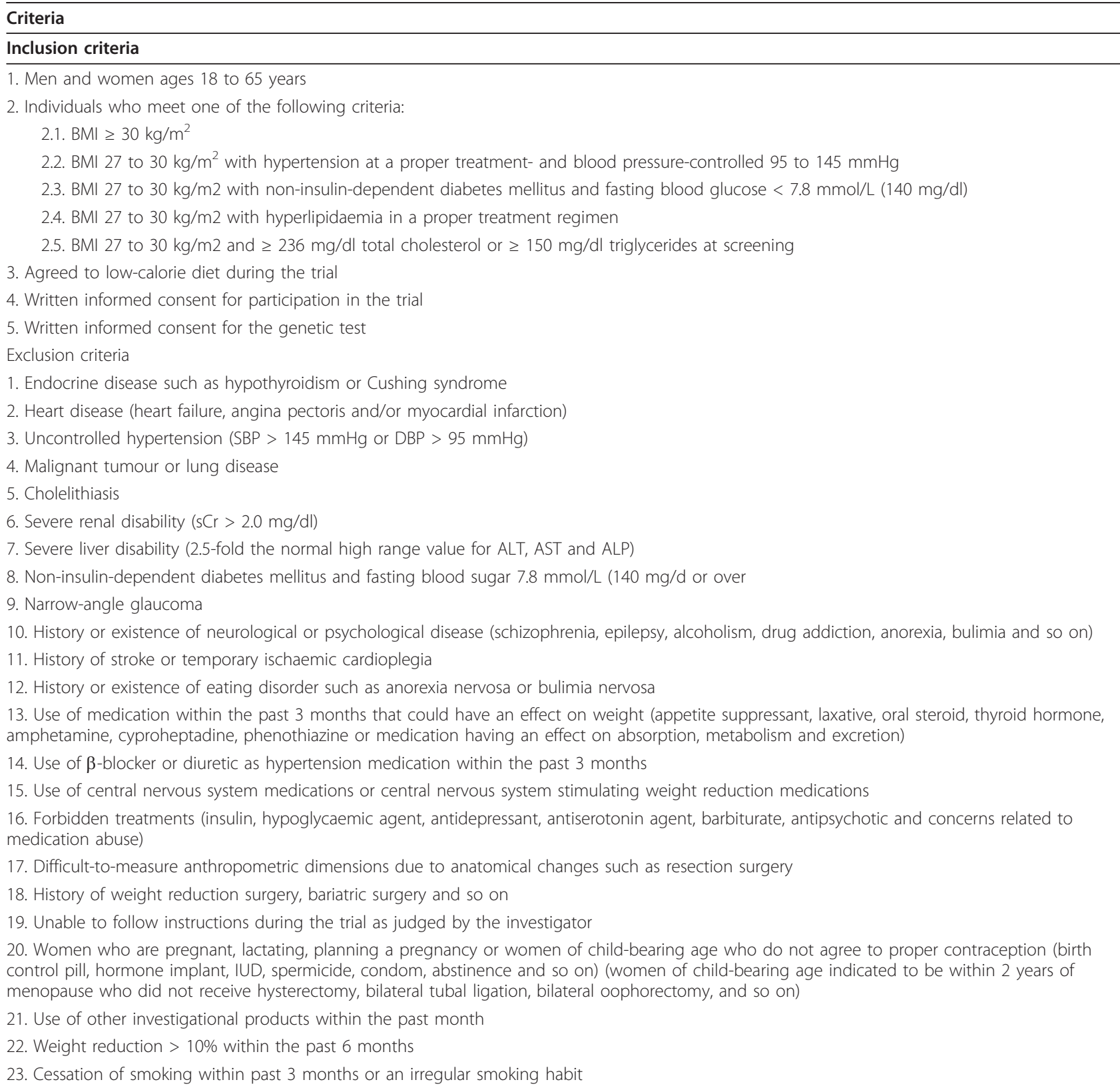

${ }^{\text {a } A L P}$ alkaline phosphatase, $A L T$ alanine aminotransferase, ASTaspartate aminotransferase, $B M I$ body mass index, DBP diastolic blood pressure, IUD intrauterine device; SBP systolic blood pressure, $s C r$, serum creatinine

\section{Table 2 Subject withdrawal criteria}

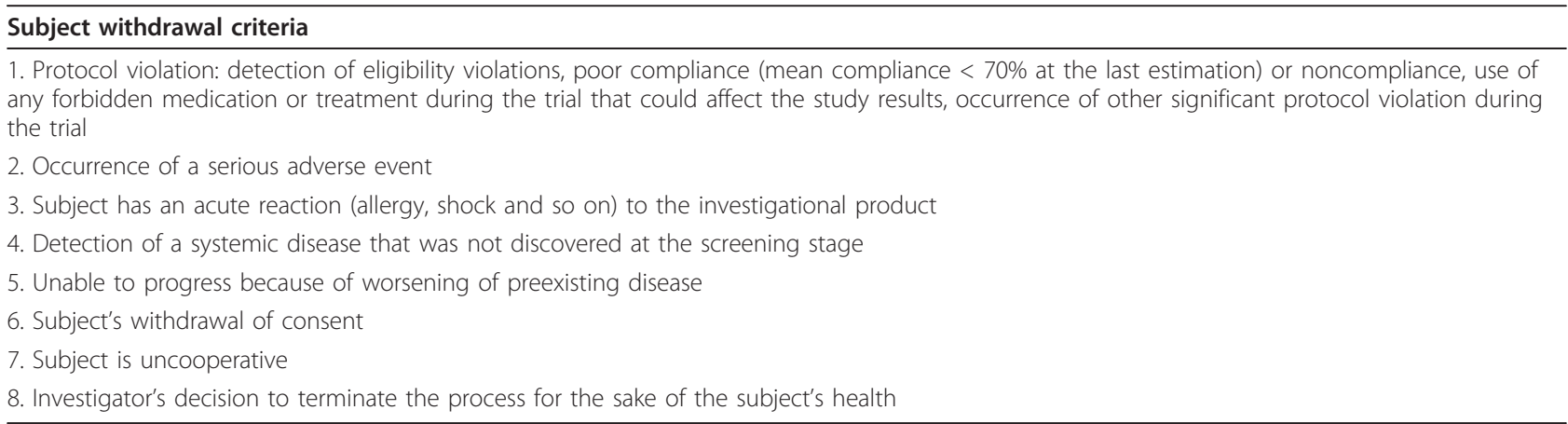


Table 3 Constituents of interventions (TJ001 and placebo) $^{\mathrm{a}}$

\begin{tabular}{lccc}
\hline & $\begin{array}{c}\text { TJ001 } \\
\text { extract }\end{array}$ & & \\
\hline Name of herb & Raw material code & $\begin{array}{c}\text { Dose } \\
(\mathbf{g})\end{array}$ & $\begin{array}{c}\text { Content } \\
\text { (\%) }\end{array}$ \\
\hline Semen Coicis & M040487 & 3.75 & NA \\
Semen Castaneae & M089646 & 3.75 & NA \\
Semen Raphani & M210181 & 2.5 & NA \\
Schisandrae Fructus & M040445 & 1.25 & NA \\
Liriopis tuber & M040139 & 1.25 & NA \\
Herba Ephedrae & M040135 & 1.25 & NA \\
Radix platycodi & M040048 & 1.25 & NA \\
Acori Tatarinowii & M051377 & 1.25 & NA \\
Rhizoma & Placebo & & \\
Composition & Raw material code & Dose & Content \\
& & & $(\%)$ \\
Lactose & NA & NA & $87.99 \%$ \\
Starch & NA & NA & $11.73 \%$ \\
Food colouring & NA & NA & $0.28 \%$ \\
\hline
\end{tabular}

${ }^{a} N A$ not applicable. ${ }^{b}$ Korea Ministry for Health and Welfare classification 233 (ATC code A16AX).

usual exercise levels. However, intense, unusual workouts will not be permitted.

\section{Concomitant treatments and forbidden drugs}

The subjects will be permitted to use medications only with the investigator's permission. The product name, use, dosage and duration of these medications will be recorded. The following concomitant treatments will be prohibited: central nervous system medications; central nervous system stimulating weight reduction medications; medications that could have an effect on weight (insulin, hypoglycaemic agents, oral steroids, thyroid hormones, cyproheptadine and phenothiazine); medications that affect absorption, metabolism or excretion; $\beta$-blockers and diuretics for hypertension treatment; amphetamines; antidepressants; antiserotonin agents; barbiturates; antipsychotics; and medicines that increase blood pressure or pulse, including decongestants that contain phenylpropanolamine, ephedrine or pseudoephedrine as well as medicines for coughs, common colds and allergies.

\section{Sample size calculation}

A sample size of 104 subjects was estimated for $80 \%$ power at a significance level of 0.05 and an attrition rate of $20 \%$. Participants will be selected according to the eligibility criteria.

No preliminary studies of TJ001 were available to aid in estimating the percentage of subjects with $5 \%$ or greater weight loss [21]. Therefore, we set the rate at $40 \%$ for the TJ001 group and 13\% for the placebo group on the basis of a reference paper [28]. The formula for calculating the sample size when allocating subjects at a ratio of 1:1 (TJ001:placebo) is as follows:

$$
\begin{aligned}
n & =\frac{\left\{z_{1-\alpha} \sqrt{2 \bar{p}(1-\bar{p})}+z_{1-\beta} \sqrt{p_{t}\left(1-p_{t}\right)+p_{c}\left(1-p_{c}\right)}\right\}^{2}}{\left(p_{t}-p_{c}\right)^{2}} \\
& =\frac{\{1.96 \sqrt{2(0.265)(0.735)}+0.84 \sqrt{(0.40)(0.735)+(0.13)(0.87)}\}^{2}}{(0.40-0.13)^{2}} \approx 41
\end{aligned}
$$

$p_{t}$

The $5 \%$ or greater responder rate of the initial weight in TJ001 group $=40 \%$.

$p_{c}$

The $5 \%$ or greater responder rate of the initial weight in the placebo group $=13 \%$.

$$
\bar{p}:\left(p_{t}+p_{c}\right) / 2=26.5 \% \quad z_{1-\alpha / 2}=1.96, \quad z_{1-\beta}=0.84
$$

Allowing for an attrition rate of $20 \%$, the number of subjects in each group is 52 .

$$
n^{*}=\frac{n}{(1-0.2)}=51.25 \approx 52
$$

Therefore, a total of 104 subjects are needed for this trial.

\section{Randomisation method}

The study subjects who satisfy the eligibility criteria will be randomised using a web-based randomisation program at an independent centre (Medical Research Collaborating Center of Seoul National University Hospital http://mrcc. snuh.org/). This program will be set to allocate participants equally to each site at a ratio of $1: 1$. Each of the four sites will be allocated 26 participants. The TJ001 and placebo groups will each be allocated 52 participants. The randomisation program will be designed with a fourpatient block randomisation.

\section{Blinding}

Both the investigator and the subject will be blinded regarding the assignment of the study drugs. The contract research organisation (CRO; Kyung Hee University, Center for Clinical Research and Genomics) of the sponsor will label the investigational drugs by the randomisation code number. The labelled experimental products will be provided to the trial sites by the CRO.

\section{Recruitment}

Participants will be recruited through posted notes on the bulletin boards at four hospitals: Catholic University of Korea Seoul St Mary's Hospital (located in Seoul, South Korea), Dongguk University Ilsan Oriental Hospital, Kyungwon Gil Oriental Medical Hospital (Ilsan and Incheon, South Korea, both satellite cities near Seoul) and Semyung University Oriental Medicine Hospital 
(Chungju, a midsized city located in central South Korea).

\section{Study schedule}

The measurements that need to be carried out at each visit are listed in Table 4.

\section{Measurement tools \\ Anthropometric measuring for height, weight, waist circumference and hip circumference}

All measurements will be taken by well-trained examiners using standard procedures. Measurements will be made while participants are dressed in light garments and with bare feet. Height and weight will be measured in the standing position to the nearest $0.1 \mathrm{~cm}$ and 0.1 $\mathrm{kg}$, respectively. A measuring rod with a movable headpiece will be mounted on a balance beam scale. The waist circumference (WC), recorded to the nearest $0.1 \mathrm{~cm}$, will be measured midway between the lower margin of the last rib and the top of the pelvic bone in a horizontal plane using plastic tape. The hip circumference $(\mathrm{HC})$, recorded to the nearest $0.1 \mathrm{~cm}$, will be measured at the horizontal level of the widest part of the hip. BMI is calculated by dividing weight in kilograms by height in square meters [29]. We will record the subjects' weight loss in kilograms at every visit and calculate BMI and the rate of monthly weight loss in both groups [30].

\section{Questionnaires}

Questionnaire for the Sasang Constitution Classification II The Questionnaire for the Sasang Constitution Classification II Sasang Constitution Classification II

Table 4 Study schedule of TJ001 clinical trial (12 weeks) ${ }^{a}$

\begin{tabular}{|c|c|c|c|c|c|}
\hline \multirow[b]{2}{*}{ Measurement items } & \multirow{2}{*}{$\begin{array}{c}\text { Initial } \\
\text { screening b } \\
\begin{array}{c}\text { Visit } 1 \text { (-7 } \\
\text { days) }\end{array}\end{array}$} & \multicolumn{4}{|c|}{ Treatment period } \\
\hline & & $\begin{array}{l}\text { Visit } 2 \text {, week } 0 \\
\text { (0 days) }\end{array}$ & $\begin{array}{l}\text { Visit } 3,4 \text { weeks } \\
\text { (28 days) }\end{array}$ & $\begin{array}{l}\text { Visit } 4,8 \text { weeks } \\
\text { (56 days) }\end{array}$ & $\begin{array}{c}\text { Visit } 5,12 \text { weeks } \\
\text { (84 days) }\end{array}$ \\
\hline Informed consent & Yes & & & & \\
\hline Demographic characteristics ${ }^{c}$ & Yes & & & & \\
\hline Vital signs $^{d}$ & Yes & Yes & Yes & Yes & Yes \\
\hline Medical/drug use history & Yes & & & & \\
\hline Smoking/drinking status & Yes & & Yes & Yes & Yes \\
\hline Physical examination ${ }^{e}$ & Yes & Yes & Yes & Yes & Yes \\
\hline Laboratory tests ${ }^{f}$ & Yes & & & & Yes \\
\hline Thyroid hormones ${ }^{g}$ & Yes & & & & \\
\hline Lipid test, CRP level ${ }^{\text {h }}$ & & Yes & & & Yes \\
\hline Abdominal computed tomography for body fat & & Yes & & & Yes \\
\hline Blood sample for genetic test & & Yes & & & \\
\hline Electrocardiography & Yes & & & & \\
\hline Pregnancy test & Yes & & & Yes & Yes \\
\hline Inclusion/exclusion criteria check & & Yes & & & \\
\hline Dietary intake measurement ${ }^{\mathrm{i}}$ & & Yes & Yes & Yes & Yes \\
\hline Concomitant medication & & Yes & Yes & Yes & Yes \\
\hline Adverse event & & & Yes & Yes & Yes \\
\hline Questionnaires ${ }^{j}$ & & Yes & & & Yes \\
\hline \multicolumn{6}{|l|}{ Questionnaire for Sasang } \\
\hline Constitution Classification & Yes & & & & \\
\hline \multicolumn{6}{|l|}{$\|$} \\
\hline \multicolumn{6}{|l|}{ Exterior Cold } \\
\hline Disease induced from the & & Yes & Yes & Yes & Yes \\
\hline \multicolumn{6}{|l|}{ Esophagus affected by } \\
\hline $\begin{array}{l}\text { Cold' questionnaire in Tae-Eum-In persons } \\
\text { Compliance calculation }\end{array}$ & & & Yes & Yes & Yes \\
\hline $\begin{array}{l}{ }^{a} C R P \text { C-reactive protein. }{ }^{b} \text { The initial screening is perfo } \\
{ }^{\mathrm{c}} \text { Sex, date of birth, age, contact address and telephor } \\
\text { height }(\mathrm{cm}) \text {, waist circumference }(\mathrm{cm}) \text { and hip circum } \\
\text { count, platelet count, total protein, albumin, total bili } \\
\text { nitrogen/creatinine ratio, fasting plasma glucose, crea } \\
\text { nitrite, red blood cells and white blood cells. }{ }^{9} \text { Thyroi } \\
\text { high-density lipoprotein cholesterol (mg/dl), triglyceri } \\
\text { research coordinator. }{ }^{\mathrm{j} K o r e a n} \text { obesity-related quality }\end{array}$ & $\begin{array}{l}\text { rmed within } 1 \mathrm{w} \\
\text { ee number. }{ }^{\mathrm{d}} \mathrm{Bloo} \\
\text { ference }(\mathrm{cm}) .{ }^{\mathrm{f}} \mathrm{Bl} \\
\text { ubin, alanine tra } \\
\text { tinine kinase anc } \\
\text {-stimulating hor } \\
\text { de }(\mathrm{mg} / \mathrm{dl}) \text { and } \mathrm{C}\end{array}$ & $\begin{array}{l}\text { ek of the start of th } \\
\text { pressure }(\mathrm{mmHg}), \mathrm{p} \\
\text { sd tests are perform } \\
\text { saminase, aspartate } \\
\text { urine test for colour } \\
\text { one and free thyrox } \\
\text { P. 'Recorded in kiloc }\end{array}$ & $\begin{array}{l}\text { tudy period. The visi } \\
\text { se (beats/minute) an } \\
\text { for haemoglobin, he } \\
\text { nsaminase, alkaline } \gamma \\
\text { ecific gravity, } \mathrm{pH} \text {, pr } \\
\text { are measured at th }\end{array}$ & $\begin{array}{l}\text { indows for each par } \\
\text { ody temperature }\left({ }^{\circ} \mathrm{C}\right. \\
\text { tocrit, red blood cell } \\
\text { utamyltransferase, u } \\
\text { in, glucose, ketone, } \\
\text { ime of screening. }{ }^{\mathrm{h}} \mathrm{Tc} \\
\text { ary recall methods b }\end{array}$ & $\begin{array}{l}\text { pant are } \pm 3 \text { days. } \\
{ }^{B} \text { Body weight }(\mathrm{kg}) \text {, } \\
\text { ount, white blood cell } \\
\text { acid, blood urea } \\
\text { obilinogen, bilirubin, } \\
\text { al cholesterol (mg/dl), } \\
\text { a dietician or clinical }\end{array}$ \\
\hline
\end{tabular}


classifies a person into one of four types of constitution according to personal traits based on I Je-ma's Sasang constitutional medicine theory [31]. We will use this questionnaire to classify obese Korean adults. Additionally, we will use this questionnaire to evaluate whether there is an association between each constitutional type and the effect of TJ001.

Exterior Cold Disease induced from the Oesophagus affected by Cold questionnaire in Tae-Eum persons Exterior Cold Disease induced from the Esophagus affected by Cold questionnaire is used to evaluate symptoms that can occur in people of the Tae-Eum constitutional type according to the Sasang constitutional medicine theory [8]. We will apply this questionnaire to examine whether there is a relationship between the tendency toward obesity in Tae-Eum persons and their response to TJ001.

Compliance All subjects will be asked to return the remaining investigational products at their next visit, and the rate of compliance (percentage) will be calculated on the basis of the returned products.

Compliance $(\%)=100-$ returned products/expected intake $\times 100$.

Investigational drugs will be distributed in packs of 100 at each visit.

$100=3$ times $/$ day $\times 7$ days/week $\times 4$ weeks/visit +16 extras.

\section{Outcomes}

Both primary and secondary end points will be measured at each visit according to the study schedule (Table 4).

\section{Primary outcome}

The primary outcome is the rate of subjects who have lost $5 \%$ or more of their baseline body weight $[28,30,32]$.

\section{Secondary outcomes}

Both within-group and between-group analyses will be performed for each outcome. The differences in the following variables between the baseline (visit 1) and the last visit (visit 5) will be calculated.

- Body weight $(\mathrm{kg})$

- BMI $\left(\mathrm{kg} / \mathrm{m}^{2}\right)$

- $\mathrm{WC}(\mathrm{cm})$

- $\mathrm{HC}(\mathrm{cm})$

- Waist/hip circumference ratio (WHR) change

Lipid profile: total cholesterol, triglyceride, HDL cholesterol, LDL cholesterol levels (mg/dl) (LDL cholesterol will be estimated using the Friedewald equation [33].)

Body fat composition: visceral fat area $\left(\mathrm{cm}^{2}\right)$ and subcutaneous fat area $\left(\mathrm{cm}^{2}\right)$ (Body composition will be evaluated by abdominal computed tomography.)

- Blood pressure (mmHg)

- Fasting plasma glucose concentration (mg/dl)
- C-reactive protein (mg/L) Questionnaires scores: Korean Obesity-related Quality of Life (KOQOL) and Korean version of Eating Attitudes Test-26 (KEAT-26)

\section{Safety outcomes}

All variables related to the safety assessment such as vital signs, general physical examinations, various test results (hematologic tests, biochemical tests, and urine tests) and adverse events (AEs) will be documented on the case report form (CRF) at every visit.

\section{Statistical analysis \\ Efficacy assessment}

The primary outcome will be analysed using the intention-to-treat (ITT) method. The secondary outcomes will be assessed by both the ITT and the per-protocol (PP) methods. The full analysis set for ITT method will include all randomised subjects, regardless of their subsequent withdrawal after enrolment. The PP analysis will include patients who have completed the 12-week study term without any major protocol violations and have a compliance rate $>70 \%$. Missing values will be replaced by using the last observation carried forward method. Continuous variables will be reported as means $\pm S D$, and categorical variables will be reported as percentages. The baseline characteristics will be compared by either Student's $t$-test for continuous variables or the $\chi^{2}$ test (Fisher's exact test when the expected value is $<5$ ) for categorical data. Alternatively, McNemar's test will be used if the normality assumption is not satisfied for the continuous variables.

For the within-group analyses, primary and secondary outcome variables will be evaluated by using a paired $t$ test. Alternatively, for nonnormal distribution data, the Wilcoxon test will be performed. Analysis of covariance will be applied to analyse differences in each group at every visit, adjusting for age, baseline weight and BMI as covariates. Between-group comparisons for each variable will be performed using Student's $t$-test. Statistical significance will be defined as $P<0.05$. PASW for Windows version 18.0 software (SPSS, Inc, Chicago, IL, USA) will be used for the analyses.

\section{Safety assessment}

Safety analyses will be performed for all subjects, who will be randomised and visited more than once after the initial screening. Safety-related variables will be analysed using the ITT method. Safety data will be stratified according to symptoms.

\section{Adverse event reporting}

AEs will be recorded in medical diagnostic terminology. Detailed symptoms, duration, severity, causal relationships, actions taken, results and other information will be recorded for each AE. All AEs must be observed and recorded in the CRF in the AE report section. When an 
AE occurs, investigators should notify both the IRB and the regulatory authorities within 24 hours.

\section{Data quality control, data collection and data management}

Data quality control will be achieved through monitoring during the trial. After checking the written CRF, welltrained clinical research associates of the CRO will collect the data. Data management will be performed by the CRO, Center for Clinical Research and Genomics, Seoul, Republic of Korea. All processes will be conducted using standard operating procedures.

\section{Ethical issues}

This study has been approved by the institutional review boards (IRBs) at each of the four institutions: the IRB of the Catholic University of Korea Seoul St Mary's Hospital (reference KC09MNME0032), the IRB of the Dongguk University Ilsan Oriental Hospital (ref: SR-09), the IRB of the Semyung University Oriental Medicine Hospital (reference 2008-03) and the IRB of the Kyungwon Gil Oriental Medical Hospital (reference 08-101)). Written informed consent will be obtained from each individual prior to enrolment. Research will be performed in compliance with the Helsinki Declaration and with the Good Clinical Practice Guidelines.

\section{Discussion}

By exploring estimated obesity-related variables, our aim in this pilot study is to determine the precise target population, the primary end point and the intervention period. Throughout the trial we will evaluate the efficacy and safety of Taeumjowi-tang. Korea has a dual medical treatment system, and herbal medicine assessments are under special regulations as described in the WHO legal status review of traditional medicine. For traditional Korean medicinal herbs, the Korea Food and Drug Administration rules specify that they are permitted to be produced $[34,35]$ if herbal preparations are listed in the 11 classic traditional Korean and Chinese medicine books [36]. As these preparations are considered to have historical evidence of efficacy and safety, clinical or toxicological results can be exempted. Our intervention, Taeumjowi-tang, is described in one of these classic medical books, the Donguisusebowon [8]. Despite its long history and widespread usage, few Taeumjowi-tang trials have been published $[21,27,37]$. Therefore, our trial could be considered a pilot study, and the efficacy and safety of Taeumjowitang should be assessed in a RCT.

We encountered difficulties in deciding several issues. First, we had difficulty in selecting the target population. We considered using stratified randomisation, because weight reduction is affected by sex, age and physical baseline characteristics such as initial weight and BMI
$[3,38,39]$. However, these various strata would decrease the statistical power. We first needed to determine the general patterns of Korean obesity. To maximise both the power and the results within given research budgets, we will include adults over age 18 years and both sexes. We will carry out stratified analyses with sex as a stratum. Other covariates, such as age, weight and BMI at the initial screening visit, will be adjusted.

The second question was what the primary end point would be. Among various outcomes [40,41], we set a 5\% or greater weight loss responder rate as the primary outcome because $5 \%$ or greater weight loss is considered to be clinically significant $[28,30,32]$. As the amount of weight loss can vary due to initial weight, our study team concluded that the rate of the subjects who achieved a weight loss of $5 \%$ or more from their baseline weight would be reasonable compared to the absolute weight change. Other parameters, such as BMI, weight, body fat composition and WHR, were set as secondary outcomes.

Third, we had difficulty in determining the treatment duration. Though a short-term medication period for chronic treatment may not be sufficient to observe accurate long-term effects $[22,42]$, we prioritised feasibility. We decided on a 12-week treatment for the trial after reflecting on the opinions of the clinicians' general experiences and considering both the attrition rate and the effectiveness of the preparation. Attrition rate will increase if the treatment duration is prolonged for more than 3 months. Additionally, according to data reported in the literature $[21,27,32,43,44]$, the intervention period of weight reduction ranges from 1 day to 18 months for complementary therapy RCTs. Among complementary therapy RCTs, 8-week and 12-week trials are the most common $[23,26,27,44]$.

\section{Conclusions}

We will assess the efficacy and safety of TJ001 in this trial. On the basis of our research results, we will be able to determine an adequate target population, a valid primary end point and an adequate treatment duration for TJ001. These results will be used to guide a future large-scale study. In addition, we expect that the results regarding the relationship between Sasang typology and obesity will lead us closer to personalised medicine.

\section{Trial status}

The trial was first designed in 2009, and the study began the same year. The study is ongoing, and subject recruitment has not been completed.

\section{Abbreviations}

AE: Adverse event; ATC: Anatomical therapeutic chemical classification; BMI: Body mass index; CRF: Case report form; CRO: Contract research 
organisation; CRP: C-reactive protein; ECDEC: Exterior cold disease induced from the oesophagus affected by cold; HC: Hip circumference; HDL: Highdensity lipoprotein; IRB: Institutional Review Board; ITT: Intention to treat; KEAT-26: Korean version of Eating Attitudes Test-26; KOQOL: Korean Obesityrelated Quality of Life; LDL: Low-density lipoprotein; PP: Per protocol; RCT: Randomised controlled trial; TJ001: Taeumjowi-tang; WC: waist circumference; WHO: World Health Organization; WHR: Waist/hip circumference ratio.

\section{Acknowledgements}

This study will be supported by a grant from the Korea Healthcare Technology R\&D Project, Ministry for Health (B080037). Additionally, the study will receive partial support from a Korea Science and Engineering Foundation (KOSEF) grant that is funded by the Korean government (Ministry of Education, Science and Technology grant 2011-0063436).

\section{Author details}

${ }^{1}$ Center for Clinical Research and Genomics, College of Oriental Medicine and Institute of Oriental Medicine, Kyung Hee University, 1 Hoegi-dong, Seoul 130-701, Republic of Korea. ${ }^{2}$ Department of Preventive Medicine, College of Oriental Medicine, Kyung Hee University, 1 Hoegi-dong, Seoul 130-701, Republic of Korea. ${ }^{3}$ Department of Oriental Rehabilitation Medicine, College of Oriental Medicine, Kyung-won University, Seongnam 461-701, Republic of Korea. ${ }^{4}$ Oriental Internal Medicine, Semyung University, Bongbang-dong, Chungju 390-711, Republic of Korea. ${ }^{5}$ Korea Institute of Oriental Medicine, 1672 Yuseongdae-ro, Daejeon 305-811, Republic of Korea.

\section{Authors' contributions}

SGK substantially contributed to the general idea and design of the study. SGK and YKS directed the overall project and take responsibility for the project. SJP, HYG, BHJ, YCS, CHC, JSP, YJY, CSA, JAL and YKS took part in designing the protocol. S.JP, BHJ and HYG planned the data analysis. SJP drafted the manuscript. All authors read and consented to the publication of the manuscript.

\section{Competing interests}

The authors declare that they have no competing interests.

Received: 9 December 2011 Accepted: 7 April 2012

Published: 7 April 2012

\section{References}

1. World Health Organisation: International Association for the Study of Obesity, International Obesity Task Force: The Asia-Pacific Perspective: Redefining Obesity and Its Treatment Sydney: Health Communications; 2000.

2. Hofbauer KG, Nicholson JR, Boss O: The obesity epidemic: current and future pharmacological treatments. Annu Rev Pharmacol Toxicol 2007, 47:565-592.

3. Jee S, Sull J, Park J, Lee S, Ohrr H, Guallar E, Samet J: Body-mass index and mortality in Korean men and women. N Engl J Med 2006, 355:779-787.

4. Korea Centers for Disease Control and Prevention (KCDC): National Health and Nutrition Survey Microdata 2008: Prevalence of Obesity

Chungcheongbuk-do: Korea Centers for Disease Control and Prevention; 2009.

5. World Health Organization: Obesity: Preventing and Managing the Global Epidemic: Report of a WHO Consultation (WHO Technical Report Series 894) Geneva: World Health Organization; 2000.

6. Heymsfield SB, Allison DB, Vasselli JR, Pietrobelli A, Greenfield D, Nunez C: Garcinia cambogia (hydroxycitric acid) as a potential antiobesity agent: a randomized controlled trial. JAMA 1998, 280:1596-1600.

7. World Health Organization: Traditional Medicine: Growing Needs and Potential Geneva: World Health Organization; 2002 [http://apps.who.int/ medicinedocs/pdf/s2293e/s2293e.pdf], (WHO Policy Perspectives on Medicines No. 002).

8. Lee JM: Donguisusebowon [Longevity and Life Preservation in Oriental Medicine]. Seoul 1894.

9. World Health Organization: Regional Office for the Western Pacific: WHO International Standard Terminologies on Traditional Medicine in the Western Pacific Region Manila: WHO Regional Office for the Western Pacific; 2007.

10. Song I, Koh B, Lee E, Kim K, Kim D, Park S: Sasang Constitutional Medicine Seoul: Jipmoondang; 2004
11. Korean Index of Medical Specialties (KIMS) Drug Information Seoul: UBM Medica; 2011

12. Lee Jl, Park YK, Kim YJ, Kim KS, Kim KS: Effects of Taeyeumjowi-tang water extract on the mouse fed high-fat diet. Korean J Orient Int Med 2003, 24:497-507.

13. Gurley BJ, Wang P, Gardner SF: Ephedrine-type alkaloid content of nutritional supplements containing Ephedra sinica (ma-huang) as determined by high performance liquid chromatography. J Pharm SCi 1998, 87:1547-1553.

14. Hwang MJ, Shin HD, Song MY: Review of literature on herbal medicines for the treatment of obesity in Korea: mainly papers since 2000. J Oriental Rehab Med 2006, 16:65-81.

15. Kim SH, Kim Y, Kim H, Jeong K, Lee S: Research on the usage frequency of Sasang constitutional herbal formula with case record form. J Korea Inst Orient Med 2011, 17:101-106.

16. Han JS, Shin YO, Oh JK, Keum DH: Anorexigenic effect of Taeyeumjowuitang (Taiyintiaowei-tang) in obese Zucker rat. J Orient Rehab Med 2005, 15:131-145.

17. Cho SW, Park SS: Effects of Taeyeumjowee-tang on loss in body weight, plasma lipids and UCP I Revelation of fated white rats. J Korean Orient Med 2004, 25:87-97.

18. Park SM, Ahn IS, Kim DS, Kang SA, Kwon DY, Yang HJ: Anti-obesity effects of Tae-Um-Jo-Wee-Tang and Do-Dam-Tang in female rats with dietinduced obesity. J Appl Biol Chem 2010, 53:44-50.

19. Choi CH, Yang DY, Kim CH, Jung JG, Jung HW: The effects of Taeyeumjowee-tang and Taeyeumjoweebaemahwang-tang on obese rats. Korean J Herbol 2010, 25:103-109.

20. Lee JA, Kong KH, Ko HY, Bae KH, Park SY, Park KM, Song YK, Park JH, Kim HJ, Park SJ, Park JS, Ko SG: Recent topics of clinical trials in obesity and metabolic study. J Soc Korean Med Obes Res 2009, 9:15-22.

21. Park KM, Song YK, Lim HH, Lee JA, Ko HY, Park JH, Kim HJ, Park SJ, Park JS, Ko SG: Review on the research relative to Taeeumjowui-Tang (Taiyintiaowei-tang). J Soc Korean Med Obes Res 2009, 9:23-36.

22. Hackman RM, Havel PJ, Schwartz HJ, Rutledge JC, Watnik MR, Noceti EM, Stohs SJ, Stern JS, Keen CL: Multinutrient supplement containing ephedra and caffeine causes weight loss and improves metabolic risk factors in obese women: a randomized controlled trial. Int J Obes 2006, 30:1545-1556.

23. Boozer CN, Nasser JA, Heymsfield SB, Wang V, Chen G, Solomon JL: An herbal supplement containing Ma Huang-Guarana for weight loss: a randomized, double-blind trial. Int J Obes Relat Metab Disord 2001, 25:316-324.

24. Boozer CN, Daly PA, Homel P, Solomon JL, Blanchard D, Nasser JA, Strauss R, Meredith T: Herbal ephedra/caffeine for weight loss: a 6-month randomized safety and efficacy trial. Int J Obes Relat Metab Disord 2002, 26:593-604.

25. Greenway FL, De Jonge L, Blanchard D, Frisard M, Smith SR: Effect of a dietary herbal supplement containing caffeine and ephedra on weight, metabolic rate, and body composition. Obes Res 2004, 12:1152-1157.

26. Greenway FL, Liu Z, Martin CK, Kai-yuan W, Nofziger J, Rood JC, Yu Y, Amen RJ: Safety and efficacy of NT, an herbal supplement, in treating human obesity. Int J Obes (London) 2006, 30:1737-1741.

27. Pittler MH, Ernst E: Complementary therapies for reducing body weight: a systematic review. Int J Obes (London) 2005, 29:1030-1038.

28. Park CY, Kim YS, Ryu MS, Nam SY, Park HS, Kim SM: A phase 3 doubleblind, parallel-group, placebo-controlled trial of the efficacy and safety of sibutramine (Reductil) in the treatment of obese patients. Korean J Obes 2001, 10:336-347.

29. World Health Organization: Physical Status: The Use and Interpretation of Anthropometry: Report of a WHO Expert Committee (WHO Technical Report Series 854) Geneva: World Health Organization; 1995.

30. Shekelle PG, Hardy ML, Morton SC, Maglione M, Mojica WA, Suttorp MJ, Rhodes SL, Jungvig L, Gagné J: Efficacy and safety of ephedra and ephedrine for weight loss and athletic performance: a meta-analysis. JAMA 2003, 289:1537-1545.

31. Chae H, Lyoo IK, Lee SJ, Cho S, Bae H, Hong M, Shin M: An alternative way to individualized medicine: psychological and physical traits of Sasang typology. J Alternative Compl Med 2003, 9:519-528.

32. Coffey CS, Steiner D, Baker BA, Allison DB: A randomized double-blind placebo-controlled clinical trial of a product containing ephedrine, caffeine, and other ingredients from herbal sources for treatment of 
overweight and obesity in the absence of lifestyle treatment. Int I Obes Relat Metab Disord 2004, 28:1411-1419.

33. Friedewald WT, Levy RI, Fredrickson DS: Estimation of the concentration of low-density lipoprotein cholesterol in plasma, without use of the preparative ultracentrifuge. Clin Chem 1972, 18:499-502.

34. World Health Organization: Legal Status of Traditional Medicine and Complementary/Alternative Medicine: A Worldwide Review Geneva: World Health Organization; 2001.

35. Korea Food and Drug Administration (KFDA), Herbal Medicine Research Division: General Considerations of Clinical Trials for Herbal Medicine Osongeup, Chungcheongbuk-do, Korea: KFDA; 2007.

36. Korea Ministry of Health \& Welfare: Notification 1995-15 Seoul: Korea Ministry of Health \& Welfare; 1995.

37. Yoo JH, Lee EJ, Kwak CK, Sohn EH, Koh BH, Song IB, Lee KS: Clinical trial of herbal formula on weight loss in obese Korean children. Am J Chin Med 2005, 33:713-722.

38. Mokdad AH, Ford ES, Bowman BA, Dietz WH, Vinicor F, Bales VS, Marks JS: Prevalence of obesity, diabetes, and obesity-related health risk factors, 2001. JAMA 2003, 289:76-79.

39. James WP: WHO recognition of the global obesity epidemic. Int J Obes (Lond) 2008, 32(Suppl 7):S120-S126.

40. Padwal R, Li SK, Lau DC: Long-term pharmacotherapy for overweight and obesity: a systematic review and meta-analysis of randomized controlled trials. Int J Obes Relat Metab Disord 2003, 27:1437-1446.

41. Rucker D, Padwal R, Li SK, Curioni C, Lau DC: Long term pharmacotherapy for obesity and overweight: updated meta-analysis. BMJ 2007, 335:1194-1199.

42. Patel MR, Donahue M, Wilson PW, Califf RM: Clinical trial issues in weightloss therapy. Am Heart J 2006, 151:633-642.

43. Opala T, Rzymski P, Pischel I, Wilczak M, Wozniak J: Efficacy of 12 weeks supplementation of a botanical extract-based weight loss formula on body weight, body composition and blood chemistry in healthy, overweight subjects-a randomised double-blind placebo-controlled clinical trial. Eur J Med Res 2006, 11:343-350.

44. Hasani-Ranjbar S, Nayebi N, Larijani B, Abdollahi M: A systematic review of the efficacy and safety of herbal medicines used in the treatment of obesity. World J Gastroenterol 2009, 15:3073-3085.

doi:10.1186/1745-6215-13-33

Cite this article as: Park et al:: A pilot study to evaluate the effect of Taeumjowi-tang on obesity in Korean adults: study protocol for a randomised, double-blind, placebo-controlled, multicentre trial. Trials 2012 13:33.

\section{Submit your next manuscript to BioMed Central and take full advantage of:}

- Convenient online submission

- Thorough peer review

- No space constraints or color figure charges

- Immediate publication on acceptance

- Inclusion in PubMed, CAS, Scopus and Google Scholar

- Research which is freely available for redistribution

Submit your manuscript at www.biomedcentral.com/submit
Biomed Central 